\title{
Epistemology socialized
}

\section{Adrian Haddock, Alan Millar, and Duncan Pritchard (eds): Social epistemology. Oxford: Oxford University Press, 2010, xviii+350pp, $£ 45.00 \mathrm{HB}$}

\author{
Jeroen de Ridder
}

Published online: 28 June 2011

(C) The Author(s) 2011. This article is published with open access at Springerlink.com

It is by now commonplace that analytic epistemology has moved beyond its oftlamented obsession of safeguarding the analysis of knowledge from Gettier cases. One outflow of post-Gettier epistemology is the scrutiny of the social dimensions of knowing and believing. There are lively debates about testimony, assertion, disagreement, group knowledge, collective practices of inquiry, epistemic division of labor, etc. The present volume (not to be confused with Fuller (2002) and Goldman and Whitcomb (2011), which share the same title) offers a representative sampling of the kinds of issues that are discussed under the heading of social epistemology. It contains fifteen original essays, some of which, I should say, are more clearly related to the social than others. Contributors are: Alvin Goldman, Lorraine Code, Miranda Fricker, Klemens Kappel, Jonathan Kvanvig, Matthew Chrisman, Paul Faulkner, Peter Graham, Alan Millar, Ram Neta, Frederick Schmitt, Sanford Goldberg, Michael Lynch, Ernest Sosa and Jennifer Lackey. In the short scope of this review, I'll summarize and comment on the essays that stood out for me.

The opening essay by Goldman usefully maps the field by introducing three different forms social epistemology might take: revisionism, preservationism and expansionism. Revisionism rejects much of the tenets of traditional analytic epistemology and opts for a relativistic framework, taking its cues from postmodernism, social constructivism, and sociological and anthropological studies of science and technology. In contrast, preservationism follows in the footsteps of traditional analytic epistemology, but focuses on the social aspects of individual agents' knowledge, discussing topics such as testimony, trust, disagreement, and social decision-making and evidence gathering. Expansionism gives the social an even more prominent role by focusing on collective agents and practices. It

\footnotetext{
J. de Ridder $(\bowtie)$

Faculty of Philosophy, VU University Amsterdam, De Boelelaan 1105,

1081 HV Amsterdam, The Netherlands

e-mail: g.j.de.ridder@vu.nl
} 
investigates collective belief and knowledge and the epistemic aspects of social practices such as science, democracy and legal adjudication. I found Goldman's pronouncements about which of these may count as "real epistemology" less useful. I'd say that's just a matter of stipulation.

Drawing on Miranda Fricker's work on epistemic injustice and feminist epistemology, Code does an excellent job of pointing out that many epistemological analyses of testimony start from unrealistic assumptions in that they fail to take into account social-political inequalities and difference in "conceptual resources" between communicating parties. These inequalities and differences matter epistemically because they make it difficult for some parties to get their testimony heard, understood and believed, or even articulated. She supports her claims with rich empirical case studies. I had serious reservations, however, about the revisionist packaging and jargon in which Code wraps her message. I think she is right that traditional epistemology would do well to take the kinds of social-political factors she talks about onboard, but I fail to see why that would imply serious revision rather than expansion of the field.

Kappel's contribution both elucidates and evaluates Craig's (1990) genealogical approach to understanding knowledge, which features prominently in several other essays as well. According to Craig, the concept of knowledge evolved out of that of a good informant and functions to flag approved sources of information. Kappel rightfully insists that this approach raises a host of difficult questions: What's the empirical evidence for the proposed genealogy and, if there isn't any, then what is its exact status? Aren't there (many) equally plausible alternatives? In what sense do concepts evolve out of, and influence, one another? What does it mean for a concept to have a point and why should we think we have a good grip on the alleged point of concepts? Instead of a genealogical approach, he proposes the less demanding idea of a "practical explication". This has two steps: first, one identifies a need humans have, based on facts about their nature, interests and environment. Then, one argues that a particular concept fulfills this need. Ascribing knowledge, Kappel suggests, may be what we use to stop inquiry. I thought that the idea of a practical explication indeed avoids some of the problems for Craig's genealogical approach, but one may well worry that some of Kappel's critical remarks about the latter apply equally to his own proposal.

Graham develops a compelling account of why we are entitled to accept testimony. More precisely, he argues that beliefs formed through our capacity of comprehension-with-filtering enjoy prima facie pro tanto entitlement in Tyler Burge's sense, i.e., they have positive epistemic status without being based on an explicit reason-based justification. His argument for this turns on the claim that comprehension-with-filtering has inducing true beliefs reliably as its etiological function. Instead of a quasi-fictional genealogical account, Graham draws on psychological research about the function of language, assertion, listening, comprehension and filtering. I think one might raise quibbles about the details of his account of etiological functions or about how good the empirical evidence we have for the origin and uses of language, comprehension, etc. really is, but the overall picture seemed right to me. Graham's conclusions are very similar in spirit to Millar's claim that we can acquire knowledge through being told. Millar, 
however, construes tellings as moves in a social practice of sharing knowledge and thus avoids potential worries about the accuracy of the historical information on which Graham's arguments depend. Instead of filtering, Millar talks about the importance of having the right kind of recognitional ability or sensitivity to discriminate untrustworthy from trustworthy tellings.

Goldberg looks at cases in which we come to know that something is not the case by inferring it from the fact that relevant sources are silent. To identify the conditions under which such an inference is warranted, he draws an analogy between memory and testimony. Two factors are crucial in both cases: the coverage of the source, i.e., to what extent the source would be likely to find out that $p$ if $p$ were the case, and the reliability of the transmission, i.e., to what extent the source would report that $p$ in such a way that the hearer would be likely come across the report. If coverage and reliability are good, a hearer can infer that $p$ is not the case from silence of the relevant sources by relying on a rule like "If no source has reported that $p$, then not- $p$." I found myself mostly in agreement, except for one point. Goldberg insists that a belief that not- $p$ can only qualify as knowledge when it is formed through an inference based on a conscious belief that the above rule holds. I don't see why that should be so. For someone with externalist inclinations about knowledge, mere counterfactual sensitivity to the falsity of the rule should be enough, especially since Goldberg explicitly affirms that that is enough in cases of positive testimony that $p$.

Lynch's essay contains a fascinating take on particularly intractable cases of disagreement: differences of opinion about basic epistemic standards, i.e., about which belief-forming methods are epistemically good ones. Under certain conditions, such disagreements lead to fundamental epistemic incommensurability. They cannot be resolved by the usual means, since the parties do not agree on what the evidence is and how it should be weighed. In such a case, Lynch suggests the parties should look for practical rather than epistemic reasons to prefer particular belief-forming methods over others. They should deliberate, in Rawlsian fashion, about which methods are preferable from behind a veil of ignorance where the reliability of the possible methods is unknown. According to Lynch, they should then prefer methods that are repeatable, adaptable, public and widespread. In the end, I found his analysis of the problem more compelling than the proposed solution. Settling for practical rather than epistemic reasons in effect amounts to a radical revision of the project of epistemology, since practical reasons have no obvious connection with truth. In my opinion, Lynch dismisses this worry too easily.

Sosa's rich and thought-provoking contribution also focuses on disagreement. He defends the claim that it can be rational for both parties to stick to their opinions, even in a case of persistent disagreement with someone who's known to be equally intelligent and knowledgeable. One interesting suggestion he makes to account for this possibility is that both parties may have a large body of evidence that they can't access or articulate fully, but which makes it rational for them to discount their peer's opinion. I'm not confident, however, that this suggestion ultimately makes good sense for longstanding disagreements in politics, ethics, religion and philosophy. In order for someone to be rational in holding on to her beliefs here, 
she would have to conceive of herself as having inaccessible and inarticulable evidence not had by her peer in every case of disagreement. Given the pervasiveness of disagreements in these areas, such a self-image seems preposterous and this realization should then lead her to give up her beliefs after all.

Disagreement is also the topic of Lackey's contribution. She draws a useful distinction between idealized and real-life cases of disagreement and urges that we shouldn't extrapolate too easily from the idealized cases to the real-life cases. Her own view about the significance of disagreement is that whether steadfastness or conciliation is called for depends on the level of justification one has for one's beliefs. Disagreement with a peer about a belief with a low degree of justification and a significant possibility of error should move one to change one's opinion or suspend belief, whereas a firmly justified belief shouldn't just be given up because of disagreement. I felt considerable sympathy for this view, but it did leave me wondering about the consequences for philosophy and other areas where persistent disagreement abounds and where it is unclear whether we ever have high degrees of justification for what we believe. It seems that Lackey's view recommends widespread agnosticism in these areas and I find that an unattractive consequence.

It's always easy to point out that a collection of essays might have benefited from more interaction, but everyone knows that facilitating such interaction is far from easy. Nonetheless, I did feel that there were a few points where more interaction, or at least a more substantial editorial introduction, would have been very helpful. To give just two examples, Graham's notions of a practice of assertion and of comprehension-with-filtering seemed very similar to Millar's practice of tellings and the sensitivity that is required for acquiring knowledge from tellings. The reader is left wondering whether their views merely use different terminology or are genuinely different. Second, there are unexplored connections between the essays by Fricker, Faulkner and Graham in that they all rely explicitly on genealogical approaches to knowledge. Faulkner and Graham, moreover, use this approach to argue for roughly the same conclusion that there is a default entitlement to trust testimony, because there is an evolved practice of sharing information that could not have survived had it not been generally reliable. The details of their accounts, however, differ in many respects and it is difficult to see to what extent they would agree with one another. Kappel, in turn, offers what I think are penetrating critical comments on genealogical approaches. This makes one curious how Fricker, Faulkner, and Graham would have responded.

A more general observation is that it seems to me that social epistemology can and should be developed in new directions by bringing it closer to real-life social practices in which knowledge, beliefs and information play a central role and enriching it with empirical studies of these practices. Goldman (1999) took a big step in this direction, but, judging from the present volume, his example hasn't caught on widely. I, for one, would like for more epistemologists to follow Goldman's lead and start analyzing social media, the internet, science, legal practices, etc. in more detail. Another advantage of this would be that epistemology can start to appropriate the empirical material that has been collected in studies in the sociology and anthropology of science and technology, while continuing to 
reject the-to my mind-misguided antirealist and relativistic tendencies that typically run through such studies.

In the meantime, however, the editors of the present volume have done us a great service in putting together a fine collection, which should leave no doubt that social epistemology is an exciting and blossoming enterprise with a big future.

Open Access This article is distributed under the terms of the Creative Commons Attribution Noncommercial License which permits any noncommercial use, distribution, and reproduction in any medium, provided the original author(s) and source are credited.

\section{References}

Craig, Edward. 1990. Knowledge and the state of nature: an essay in conceptual synthesis. Oxford: Clarendon Press.

Fuller, Steve. 2002. Social epistemology. Bloomington: Indiana University Press.

Goldman, Alvin. 1999. Knowledge in a social world. Oxford: Oxford University Press.

Goldman, Alvin, and Dennis Whitcomb. 2011. Social epistemology: essential readings. Oxford: Oxford University Press. 